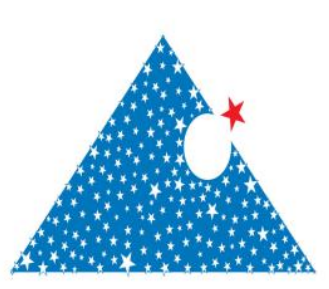

\title{
Biyodizel/Propanol Yakıt Karışımlarının Dizel Motor Emisyonlarına Etkisinin İncelenmesi
}

\author{
Doğan ŞİMŞEK ${ }^{*}$, Niyazi Yılmaz ÇOLAK ${ }^{1}$ \\ ${ }^{1}$ Bitlis Eren Üniversitesi, Teknik Bilimler MYO., Otomotiv Programı, Bitlis, Türkiye \\ dsimsek@beu.edu.tr
}

Received/Geliș: 25.09.2018

Accepted/Kabul: 25.10.2018

\begin{abstract}
Öz: Bu çalı̧̧mada, biyodizel içerisine iki farklı oranda (\%10,\%20) propanol alkolü ilave edilmiş ve tek silindirli dizel motorda test edilmiştir. Elde edilen sonuçlarda biyodizel yakıtına göre motor performansında iyileşme olduğu görülmüştür. $\mathrm{CO}, \mathrm{NO}_{\mathrm{x}}$ ve is emisyonlarının azalma eğiliminde olduğu fakat $\mathrm{HC}$ emisyonlarında ise artış olduğu tespit edilmiştir. Biyodizel içerisinde propanol ilavesi ile biyodizel yakıtının bazı dezavantajlarının ortadan kaldırılabileceği ve özellikle $\mathrm{NO}_{\mathrm{x}}$ emisyonlarında iyileşme olduğu belirlenmiştir.
\end{abstract}

Anahtar kelimeler: Dizel motor, Propanol, Biyodizel, Motor performans1, Emisyon.

\section{Investigation of the Effect on Diesel Engine Emissions of Biodiesel/ Propanol Fuel Blends}

\begin{abstract}
In this study, propanol alcohol was added to biodiesel at two different rates (10\%, 20\%) and was tested in a one-cylinder diesel engine. According to the results, engine performance improved when compared with the biodiesel fuel. It was observed in the study that the $\mathrm{CO}, \mathrm{NO}_{\mathrm{x}}$ and smoke emissions were inclined to decrease; however, $\mathrm{HC}$ emissions had the trend to increase. It was determined in the study that adding propanol to biodiesel might eliminate some disadvantages and lead to improvements especially in $\mathrm{NO}_{\mathrm{x}}$ emissions.
\end{abstract}

Keywords: Diesel engine, Propanol, Biodiesel, Engine Performance, Emission.

\section{Giriş}

Günümüz dünyasındaki sürekli artan nüfus ve aşırı kentleşme, fosil yakıtların tüketim oranında artışa neden olmaktadır. Fosil kökenli yakıt kaynaklarının tükenmesi, yakın gelecek için kaçınılmaz bir gerçektir. Ayrıca, fosil yakıtlardan çıkan sera gazı ve diğer kirletici emisyonları, sürekli olarak yaşam alanlarını kirletmekte ve küresel 1sınma gibi sorunlara neden olmaktadır. Bu durum, yenilenebilir ve daha çevreci alternatif enerji kaynağı arayışlarını da hızlandırmaktadır. Bütün bunlara ilaveten, elde edilen yeni enerji kaynağ 1 temiz ve yenilenebilir ise, bu yeni kaynakların mevcut çevresel sorunları azaltması da mümkündür. Alternatif ve yenilenebilir bir enerji kaynağı arayışı, bilim insanlarının çeşitli seçenekler ortaya koymasına neden olmaktadır. Yapılan araştırmalar, alternatif yakıt olarak biyodizel-dizel karışımlarını popüler bir seçenek haline getirmekte ve birçok bilim adamının dikkatini bu yöne çekmektedir. Bitkisel yağlardan hazırlanan biyodizelin özelliklerinin ticari dizel yakıta yakın olması nedeniyle, bu yakıtların dizel motor için alternatif olmasının bir göstergesi olarak kabul edilmektedir [1,2]. Bitkisel yağ esterleri, toksik olmayan, biyolojik olarak parçalanabilen ve yenilenebilir bir alternatif dizel yakıt olarak ilgi 
görmektedir. Bu yă̆ esterleri "biyodizel" olarak kabul edilmektedir. Bu konuda yapılan birçok araştırma, biyodizelin özelliklerinin, dizel yakıtın özelliklerine çok yakın olduğunu göstermektedir. $\mathrm{Bu}$ nedenle biyodizel, dizel motorlarda katkı yapılarak veya hiç katkı yapılmadan kullanılabilmektedir. [3]. Biyodizelin yenilenebilirliği dışında, minimum kükürt ve aromatik içeriği, daha yüksek parlama noktası, daha yüksek kayganlık, daha yüksek setan sayısı ve daha yüksek biyolojik bozunabilirlik ve toksik etkisinin olmaması gibi çeşitli avantajları vardır. Ayrıca, biyodizel ağırlıç̧a yaklaşık \% 10-11 oksijen içermektedir. Biyodizellerin dezavantajları ise viskozitesinin yüksek olması, akma noktasının yüksek olması, düşük kalori değeri ve daha düşük değişkenlik içermesidir [4]. Sıkıştırma ateşlemeli dizel motorlar için biyodizel, biyoyakıtlar arasında en akıllı seçimdir. Bitkisel yağlarla yapılan birçok çalışma, bitkisel yağların kısa süreli ve acil durumlarda kullanılabildiğini göstermiştir. Çünkü bitkisel yağlar uzun kullanım süresine bağlı olarak enjektörlerde oluşan birikintiler, piston ve segmanların birbirine yapışması, motor yağında meydana gelen seyrelme gibi birçok motor problemine sebep olduğundan dolayı, bitkisel yağların yakıt özelliklerinin iyileştirilmesine ihtiyaç duyulmaktadır [5]. Bir dizel motorda biyodizel kullanımından kaynaklanan zorluklarla karşı karşıya kalmamak için, biyodizel ile karıştırılabilen ve tamamlayıcı özelliğe sahip olan, bir yakıta ihtiyaç duyulmaktadır. Böylece, karıştırılmış yakıtlar ile motorların performans özellikleri de artırılabilmektedir. Bu alanda çalışma yapan araştırmacıların çoğu, ek yakıt veya oksijen katkısı olarak alkolü tercih etmektedir [6]. Partiküler madde (PM), NOx emisyonlarındaki sınırlamalar ve alkol difüzyon alevlerinin neredeyse hiç is emisyonu üretmiyor olması, sıkıştırma ateşlemeli motorlarda alkol-biyodizel karışımına olan ilgiyi de arttırmaktadır [7]. Literatürde dizel motorlarda propanol kullanımı ile ilgili yapılan çalışmaların oldukça sınırlı olması, propanolun cazipliğini de arttırmaktadır. Propanol, standart dizel yakıtı ile karıştırılabildiği gibi, bitkisel yağlardan elde edilen biyodizel ile birlikte kullanılarak viskoziteyi düşürmek için, seyreltici olarak da kullanılmasına da kolaylık sağlamaktadır. Hacimce \%45'in üzerindeki karışımlar, Avrupa dizel yakıt kalite normu EN590'a göre, kinematik viskozite ve daha yüksek karışım oranlarında kayganlık gereksinimlerini karşılamamaktadır [8].

Tablo 1. Kullanılan yakıtların fiziksel özellikleri.

\begin{tabular}{lccc}
\hline Özellik & D2 & Biyodizel & Propanol \\
\hline Moleküler ağırlığı $(\mathrm{kg} / \mathrm{kMol})$ & 210 & ----- & 74,12 \\
$\mathrm{C}(\%)$ & 86,13 & 77.1 & 64,82 \\
$\mathrm{H}(\%)$ & 13,87 & 12.1 & 13,49 \\
$\mathrm{O}(\%)$ & 0 & 10.8 & 21,59 \\
Setan sayıs1 & 52 & 56 & 12 \\
Yoğunluk $\left(\mathrm{kg} / \mathrm{m}^{3}\right) 15^{\circ} \mathrm{C}$ & 835 & 884 & 803,7 \\
Viskozite $\left(\mathrm{mm} / \mathrm{s}^{2}\right) 40^{\circ} \mathrm{C}$ & 2,72 & 4.51 & 1,74 \\
Alt $1 \mathrm{~s} 1 \mathrm{değer}(\mathrm{Mj} / \mathrm{kg})$ & 42,49 & 38,65 & 30,63 \\
Buharlaşma $1 \mathrm{~s} 1 \mathrm{~s} 1(\mathrm{kj} / \mathrm{kg})$ & 375 & ----- & 727,88 \\
\hline
\end{tabular}

Propanol, dizel ile karıștırma bileşeni olarak daha hafif alkollere (metanol ve etanol) potansiyel bir alternatif oluşturan, yüksek enerji yoğunluğuna sahip düz zincirli alkol olan bir 3 karbonlu yapıdadır. Propanol, öncelikle en uygun maliyetli olan okso sentezi ile petrokimyasallardan üretilmektedir [9]. Ancak fosil yakıt rezervlerinin tükenmesi endişeleri nedeniyle, bu alkolü üretmek için sürdürülebilir yöntemler geliştirilmiştir. Propanol, biyokütle veya evsel katı atıklar gibi stoklardan üretilebilir [10]. Propanol ile yapılan benzer çalışmalarda dizel motor emisyonlarında iyileşme eğilimde olduğu ancak HC emisyonlarında kötüleşme olduğu belirtilmektedir [11-13]. Bu nedenle, yapılan bu çalışmada, biyodizel yakıtının bir dezavantajı olan, yüksek viskozite ve yoğunluğunun, propanol alkolü ile seyreltilerek performans ve emisyonlar üzerindeki etkisinin iyileştirilmesi ve yapılan çalışmanın ilgili alandaki gelişmelere katkıda bulunması hedeflenmiştir. 


\section{Materyal ve Metot}

Testlerde kullanılan biyodizel transesterifikasyon yöntemi ile elde edilmiştir. Kullanılan propanol alkolü \%99 saflıkta Sigma-Aldrich firmasından temin edilmiştir. Testlerde kullanılan yakıtların fiziksel özellikleri, Tablo 1'de verilmiştir.

Tablo 2. Test motoru özellikleri

\begin{tabular}{ll}
\hline Motor Tipi & ANTOR 3 LD 510 \\
\hline Silindir Sayıs1 & 1 \\
Silindir Çap1 x Strok & $85 \times 90 \mathrm{~mm}$ \\
Silindir Hacmi & $510 \mathrm{~cm}^{3}$ \\
S1kıştırma Oranı & $17: 01$ \\
Maksimum Motor Devri & $3200 \mathrm{~d} / \mathrm{dk}$ \\
Maksimum Motor Gücü & $12 \mathrm{Hp}$ \\
Maksimum Motor Momenti & $3,5 \mathrm{~kg} . \mathrm{m} 1800 \mathrm{~d} / \mathrm{dk}$ \\
\hline
\end{tabular}

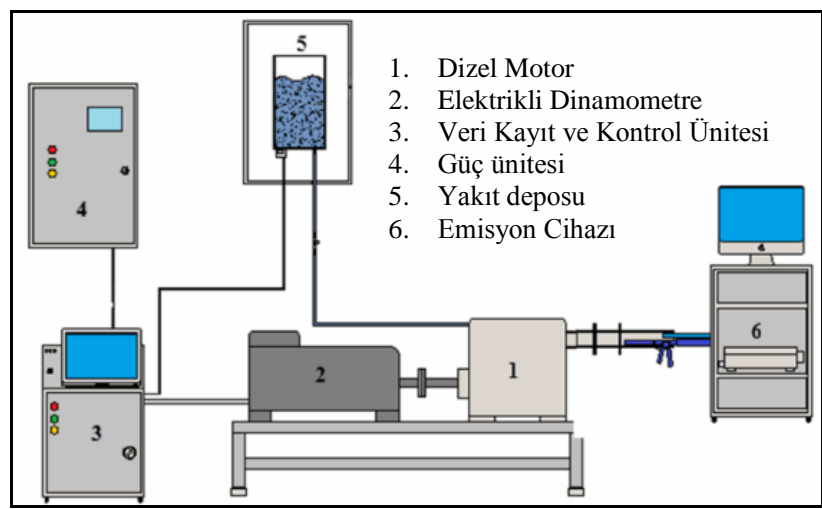

Şekil 1. Deney düzeneğinin şematik görünümü

Belirlenen yakıtların motor performans testleri, Bitlis Eren Üniversitesi, Teknik Bilimler Meslek Yüksekokulu Motorlu Araçlar ve Ulaştırma Teknolojileri Bölümü Laboratuvarlarında yapılmıştır. Motor performans test standı, Şekil 1'de şematik olarak verilmiştir. Test sisteminde $26 \mathrm{~kW}, 80 \mathrm{Nm}$ tork ve max 5000 rpm hızında elektrikli dinamometre kullanılmaktadır.

Tablo 3. Emisyon cihazı özellikleri ve ölçüm aralıkları

\begin{tabular}{lc}
\hline MOBYDIC 5000 GAZ ANALIZ CIHAZI \\
\hline $\mathrm{CO} \%$ Vol & $0-10$ \\
$\mathrm{CO}_{2} \%$ Vol & $0-20$ \\
$\mathrm{HC}$ ppm Vol & $0-20000$ \\
$\mathrm{O}_{2} \%$ Vol & $0-21$ \\
$\mathrm{NO}_{\mathrm{X}}$ ppm & $0-5000$ \\
Lambda & $0-5$ \\
$\mathrm{n} \%$ & $0-100$ \\
$\mathrm{k} 1 / \mathrm{m}$ & $0-20$ \\
Partikül mg/m & $0-1000$ \\
\hline
\end{tabular}

Test sisteminde yakıt tüketimi, motor momenti ve motor gücü verileri anlık olarak, kullanılan arayüz programı ile dijital olarak kaydedilmiştir. Sistemde yakıt tüketimi yakıt deposu altında bir yük hücresi ile saatlik yakıt tüketimini gram cinsinden ölçülmektedir. Kullanılan ara yüz programı ile üretilen saatteki motor gücüne bölünmesi ile birim güç başına düşen yakıt miktarı dijital olarak elde edilmektedir. 
Testler, tek silindirli dört zamanlı, sıkıştırma ile ateşlemeli motorda, tam gaz konumunda ve farklı motor devirlerinde test edilmiştir. Tablo 2'de, deneysel çalışmalarda kullanılan motorun özellikleri verilmiştir. Egzoz emisyonları Mobydic marka gaz analiz cihazı kullanılmıştır.

\section{Bulgular ve Tartışma}

Şekil 2'de farklı yakıt karışımlarının motor momentine etkisi verilmiştir.

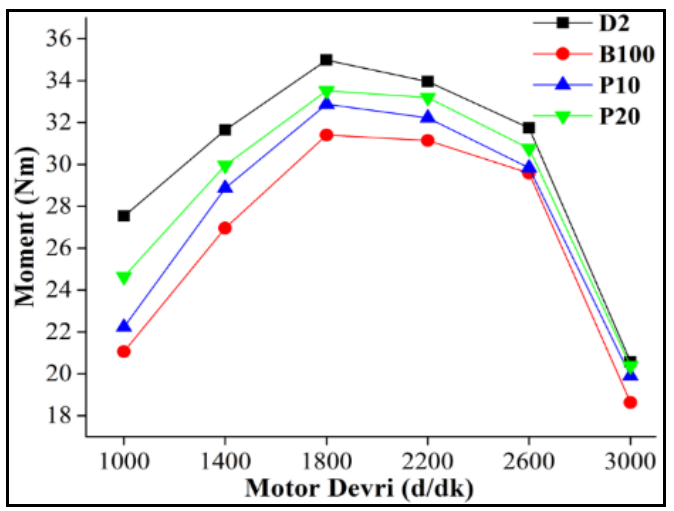

Şekil 2. Farklı yakıt ve karışımlarının motor momentine etkisi

Şekil 2'de verilen sonuçlar incelendiğinde, saf biyodizel kullanıldığında dizel yakıtına göre motor momentinde azalma olduğu görülmektedir. Maksimum momentin sağlandığ motor devrinde (1800 d/dk) dizel yakıtı ile 34,97 Nm, B100 yakıtı ile 31,40 Nm, B90P10 (\%90 biyodizel+\%10 Propanol) yakıt karışımı ile 32,87 Nm ve B80P20 (\%80 biyodizel+\%20 Propanol) yakıt karışımı ile 33,51 Nm motor momenti elde edilmiştir. Elde edilen sonuçlarda, dizel yakıtına göre B100 yakıtı kullanıldığında yaklaşık olarak \%10, P10 ile \%6 ve P20 yakıt karışımı ile \%4 oranında bir azalma olduğu görülmektedir. Motor momentindeki bu azalma biyodizel yakıtın alt 1sıl değerinin dizel yakıtına göre düşük olmasından kaynaklanmaktadır [14]. Ayrıca kullanılan biyodizelin dizel yakıtına göre yoğunluğunun ve viskozitesinin yüksek olması, püskürtme esnasında yakıt atomizasyonunu olumsuz etkilemekte ve yanmayı kötüleştirmektedir [15]. Biyodizel+alkol kullanımında ise motor momentinin, yakıt içerisinde alkol oranının artması ile arttığı görülmektedir. Mishra vd. [13] yaptıkları bir çalışmada, biyodizel yakıtı içerisinde alkol oranının artması ile yakıt karışımının yoğunluğunun azaldığını ve yanmanın daha verimli olduğunu belirtmişlerdir. Şekil 3'de farklı yakıt ve yakıt karışımlarının motor devrine göre motor gücüne etkisi verilmiştir.

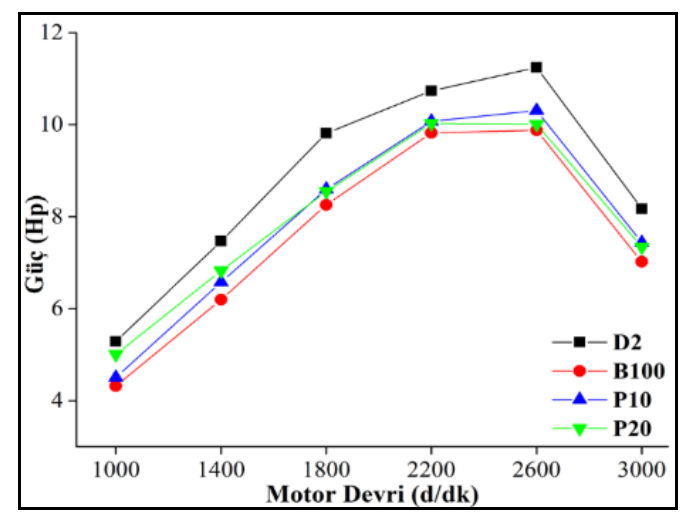

Şekil 3. Farklı yakıt ve yakıt karışımlarının motor gücüne etkisi

Şekil 3'de verilen sonuçlar incelendiğinde, biyodizel ve yakıt karışımları kullanılması durumunda motor gücünde azalma olduğu görülmektedir. Bu azalma maksimum gücün elde edildiği motor 
devrinde (2600 dev/dak) B100 yakıtı ile yaklaşık \%13, P10 yakıtı ile yaklaşık \%9, P20 yakıtı ile \%11 oranında bir azalma olduğu elde edilmiștir. Bu güç kaybı kullanılan yakıtın alt 1sıl değeri ve viskozitesi ile ilişkili olduğu önceki yapılan çalışmalarda da vurgulanmaktadır $[8,16]$. Laza ve Bereczky [11] yaptıkları bir çalışmada, yakıt viskozitesinin yüksek olmasının, püskürtülen yakıtın damlacık çapının büyümesine neden olduğunu ve yanma verimini olumsuz yönde etkilediğini belirtmişlerdir. Ayrıca, P20 yakıtı kullanılması durumunda, yüksek motor hızlarında motor gücünde azalma olduğu anlaşılmaktadır. Bu durum, biyodizel yakıtı içerisinde alkol oranının artması ile hazırlanan yakıtın, viskozitesinin azalmasına ve yanmayı olumsuz yönde etkilemesine neden olmaktadır. Daha önceki yapılan bir çalışmada, yakıtın viskozitesinin azalması silindir içerisinde püskürtme esnasında nüfuziyet derinliğini artırmakta ve alev sönümlenmesi sonucu yanma veriminin olumsuz yönde etkilendiği vurgulanmıştır [17]. Şekil 4'de farklı yakıt ve yakıt karışımlarının motor devrine göre özgül yakıt tüketimine (ÖYT) etkisi verilmiştir.

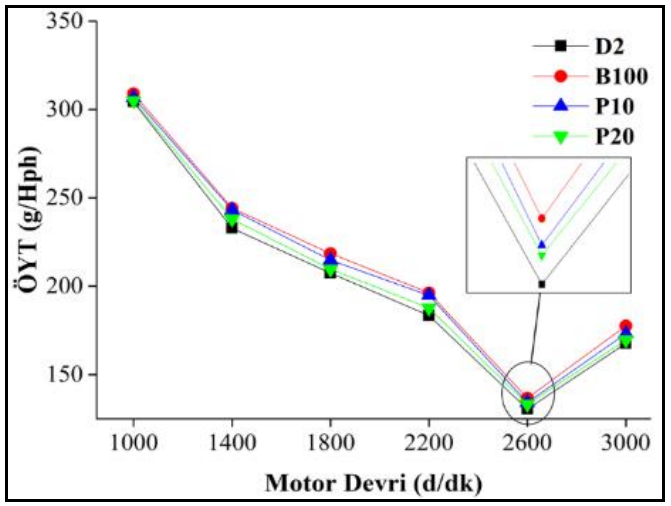

Şekil 4. Farklı yakıt ve yakıt karışımlarının motor devrine göre özgül yakıt tüketimine etkisi

Şekil 4'de verilen sonuçlar incelendiğinde, biyodizel yakıtı kullanılması ile özgül yakıt tüketiminde artma olduğu görülmektedir. Kullanılan yakıtın alt 1sıl değerinin düşük olması, aynı enerjiyi elde edebilmek için daha fazla yakıtın kullanılması, ÖYT artışının temel sebebidir [14]. Minimum ÖYT elde edildiği motor devrinde (2600 dev/dak) B100 yakıtı kullanılması ile ÖYT'de yaklaşık olarak $\% 4$, P10 yakıtı ile yaklaşık olarak \%3, P20 yakıtı kullanımında ise yaklaşık olarak \%2 oranında bir artış olduğu görülmüştür. ÖYT'nin artışının diğer bir sebebi ise, biyodizel yakıtının yoğunluğunun yüksek olması, bütün karışım oranlarında yakıtın yoğunluğunun yükselmesi ile aynı hacimde daha fazla yakıt püskürtülmesidir [18]. Biyodizel yakıtı içerisindeki alkol konsantrasyonun artması ile yakıtın yoğunluk değişimi, ÖYT tüketiminin azalmasına sebep olmaktadır. Şekil 5'de farklı yakıt ve yakıt karışımlarının motor devrine göre HC emisyonuna etkisi verilmiştir.

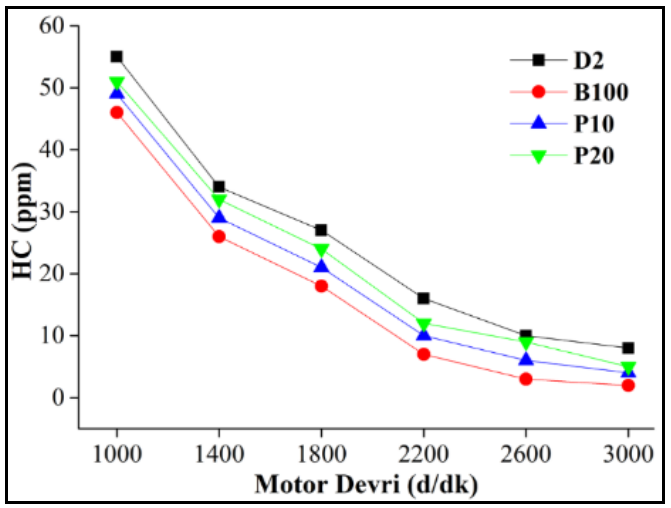

Şekil 5. Farklı yakıt ve yakıt karışımlarının HC emisyonuna etkisi 
Şekil 5'de verilen sonuçlar incelendiğinde, dizel yakıtına göre saf biyodizel kullanımında HC emisyonlarının azaldığı görülmektedir. Bu azalma, biyodizel içerisinde standart dizel yakıtına göre yapısında karbon (C) atomlarının az ve oksijenin fazla olmasından kaynaklanmaktadır [19]. Ancak biyodizel yakıtı içerinde alkol oranının artması, HC emisyonlarında artma eğilimi göstermektedir. $\mathrm{Bu}$ artış, kullanılan alkolün buharlaşma 1sısının yüksek olması nedeniyle yanmamış HC'ların artmasından kaynaklanmaktadır [20]. Maksimum güç üretilen motor devrinde (2600 dev/dak) dizel yakıt1 ile 10 ppm, B100 yakıtı ile 3 ppm, B90P10 yakıtı ile 6 ppm, B80P20 yakıtı ile 9 ppm HC emisyonları elde edilmiştir. Şekil 6'da farklı yakıt ve yakıt karışımlarının (motor devrine göre) CO emisyon değerlerindeki değişimleri verilmektedir.

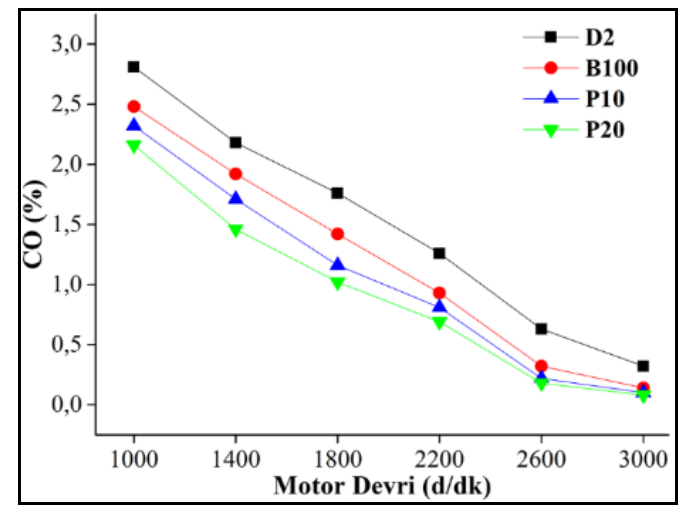

Şekil 6. Farklı yakıt ve yakıt karışımlarının CO emisyon değişimleri

Şekil 6'da verilen CO emisyon değişimleri incelendiğinde, bütün motor devirlerinde biyodizel içerisine ilave edilen alkol oranı arttıkça, CO emisyonlarında azalma olduğu görülmektedir. Maksimum güç elde edilen motor devrinde ( 2600 dev/dak) dizel yakıtı ile 0.43 , B100 yakıtı ile 0.32 , P10 yakıtı ile 0.22 ve P20 yakıtı ile 0.18 olarak kaydedilmiştir. Labeckas ve Slavinskas [21] yaptıkları bir çalışmada, $\mathrm{CO}$ emisyonlarındaki azalmanın nedeninin, biyodizelin ve alkol yapısındaki karbon (C) atomlarının az, oksijenin (O) atomlarının ise fazla olmasından kaynaklandığını vurgulamışlardır. Şekil 7'de farklı yakıt ve yakıt karışımlarının motor devrine göre $\mathrm{NO}_{\mathrm{x}}$ emisyonuna etkisi verilmiştir.

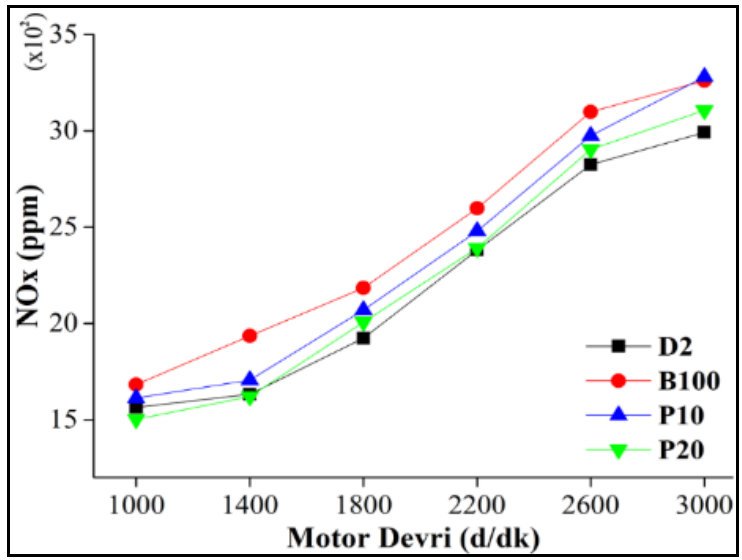

Şekil 7. Farklı yakıt ve yakıt karışımlarının $\mathrm{NO}_{\mathrm{x}}$ emisyonuna etkisi

Şekil 7'de verilen $\mathrm{NO}_{\mathrm{x}}$ emisyonu değişimleri incelendiğinde, bütün motor devirlerinde, biyodizel yakıtı kullanılması ile $\mathrm{NO}_{\mathrm{x}}$ emisyonlarının arttığı görülmektedir. İçten yanmalı motorlarda egzoz gazlarının içerisinde $\mathrm{NO}_{\mathrm{x}}$ oluşumunun temel sebebi silindir içi yüksek sıcaklıktır [19]. Biyodizel yapısında oksijen bulunması, silindir içerisinde yanma sonu sıcaklığını yükseltmektedir. Bu durum, biyodizel yakıtı ve karışımlarının kullanılmasıyla $\mathrm{NO}_{\mathrm{x}}$ emisyonlarının artmasına neden olmaktadır. 
Biyodizel ile alkol karışımları kullanıldığında ise, biyodizel yakıtına göre $\mathrm{NO}_{\mathrm{x}}$ emisyonlarında azalma meydana gelmektedir. Bu azalma, biyodizele ilave edilen alkolün daha yüksek buharlaşma 1sısına sahip olmasından dolayı, yanma sonu sıcaklığını düşürmesinden kaynaklanmaktadır [12]. Maksimum güç üretilen motor devrinde $(2600 \mathrm{~d} / \mathrm{dk}) \mathrm{NO}_{\mathrm{x}}$ değerleri dizel yakıtı ile $2824 \mathrm{ppm}, \mathrm{B} 100$ yakıt1 ile 3098 ppm, B90P10 yakıt1 ile 2975 ppm ve B80P20 yakıt1 ile 2904 ppm olarak ölçülmüştür. $\mathrm{NO}_{\mathrm{x}}$ emisyonu sonuçları daha önce yapılan çalışmalarla benzer sonuçlar göstermektedir [8,22]. Şekil 8'de farklı yakıt ve yakıt karışımlarının motor devrine göre is emisyonuna etkisi verilmektedir.

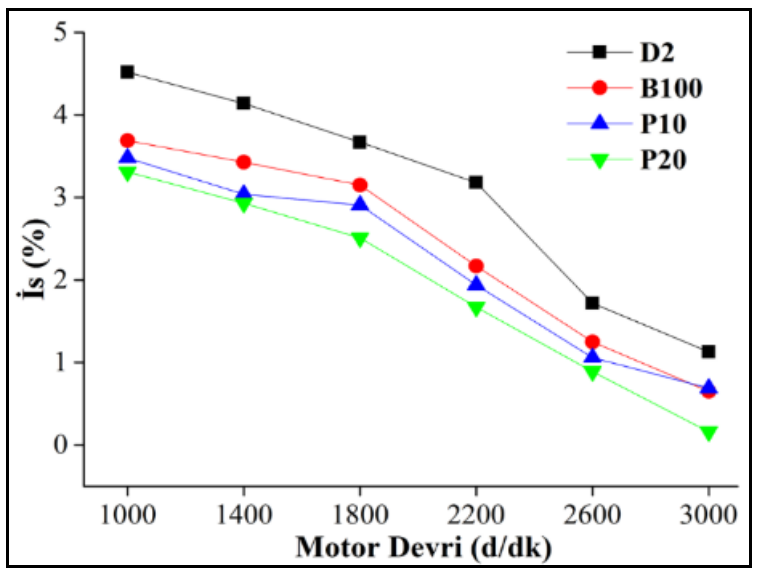

Şekil 8. Farklı yakıt ve yakıt karışımlarının is emisyonuna etkisi

Şekil 8'de verilen is emisyonu değişimleri incelendiğinde, en yüksek is emisyonu dizel yakıtı kullanılması ile elde edildiği anlaşılmaktadır. En düşük is emisyonu, P20 yakıtı kullanılması ile elde edilmiştir. Maksimum güç üretilen motor devrinde (2600 dev/dak) is emisyonu dizel yakıtı ile 1,72, B100 yakıtı ile 1,25, P10 yakıtı ile 1,06 ve P20 yakıtı ile 0,89 olarak ölçülmüştür. Biyodizel içerisinde alkol oranı arttıkça bütün motor devirlerinde is emisyonu azalmaktadır. Bu azalmanın nedeni, alkol içerisinde karbon atomlarının az ve oksijenin fazla olarak bulunmasıdır. Elde edilen sonuçlar daha önce yapılan çalışmalarla paralellik göstermektedir $[8,13,17]$.

\section{Sonuçlar}

Dizel yakıtına alternatif olarak kullanılan biyodizel yakıtı içerisine belirli oranda ilave edilen propanol alkolü ile elde edilen performans ve emisyonlarının incelendiği bu çalışmada elde edilen sonuçlar aşağıda verilmiştir.

- Biyodizel içerisinde belirli oranlarda propanol ilave edilmesi ile motor performansında azda olsa iyileşme olduğu belirlenmiştir.

- Biyodizel yakıtı içerisinde propanol oranının artması CO ve is emisyonlarında B100 yakıtına göre daha iyi sonuçlar elde edilmiştir.

- Biyodizel yakıtı içerisinde propanol oranının artması $\mathrm{NO}_{\mathrm{x}}$ emisyonunda B100 yakıtına göre azalma olduğu belirlenmiştir.

- Biyodizel yakıtı içerisinde propanol oranının artışı ile birlikte HC emisyonlarının da arttığı görülmüştür.

\section{Kaynaklar}

[1] Paul, G., Datta, A., Mandal, B. K., "An Experimental and Numerical Investigation of the Performance, Combustion and Emission Characteristics of a Diesel Engine fueled with Jatropha Biodiesel", Energy Procedia 2014, 54: 455-467. 
[2] Canaki, M., Van Garpen, J. H., "Comparison of engine performance and emissions for petroleum diesel fuel, yellow-grease biodiesel and soybean-oil biodiesel", Transactions of the ASAE, 2003, 46(4): 937-944.

[3] Graboski, MS, McCormick, RL., "Combustion of fat and vegetable-oil derived fuels in diesel engines", Progress in Energy and Combustion Science, 1998, 24: 125-164.

[4] Rakopoulos, D.C., Rakopoulos, C.D., Giakoumis, E.G., Dimaratos A.M., "Founti, Comparative environmental behavior of bus engine operating on blends of diesel fuel with four straight vegetable oils of Greek origin: sunflower, cottonseed, corn and olive", Fuel, 2011, 90: 3439-3446.

[5] Budak, N., Bayındır, H., Yücel, H. L., "Dizel Dotorlarda Biyodizel Kullanımının Performans ve Egzoz Emisyonları Açısından Değerlendirilmesi”, V. Yenilenebilir Enerji Kaynakları Sempozyumu, Diyarbakır, 19-21 Haziran 2009, 123-130.

[6] Aydin H., Ilkılıç C., "Effect of ethanol blending with biodiesel on engine performance and exhaust emissions in a CI engine", Applied Thermal Engineering, 2010, 30: 1199-1204.

[7] Cheng, C.H., Cheung, C.S., Chan, T.L., Lee, S.C., Yao, C.D., Tsang, K.S., "Comparison of emissions of a direct injection diesel engine operating on biodiesel with emulsified and fumigated methanol", Fuel, 2008, 87: 1870-1879.

[8] Kumar, B.R., Saravanan. S., "Use of higher alcohol biofuels in diesel engines: a review", Renewable and Sustainable Energy Reviews, 2016, 60: 84-115.

[9] Cornils, B., "Handbook of Commercial Catalysts. Heterogeneous Catalysts". By Howard F. Rase.2004, 2324-2325.

[10] Liu, K., Atiyeh, H. K., Stevenson, B.S., Tanner, R.S., Wilkins, M.R., Huhnke, R.L., "Continuous Syngas Fermentation for the Production of Ethanol, n-propanol and n-butanol", Bioresource Technology, 2014, 151: 69-77.

[11] Laza, T., Bereczky, Á., "Influence of Higher Alcohols on the Combustion Pressure of Diesel Engine Operated with Rape Seed Oil", Acta Mechanica Slovaca, 2009, 13(3): 54-61.

[12] Sivalakshmi, S., Balusamy T., "Performance and Emission Characteristics of a Diesel Engine Fuelled by Neem Oil Blended with Alcohols", International Journal of Ambient Energy, 2011, 32(4): 170-178.

[13] Mishra, C., Mishra, P., Kar, B., Katiyar, N., "Performance, Emission and Combustion Characteristics of an Agricultural Diesel Engine Fuelled with Blends of Calophyllum Vegetable Oil and Isopropyl Alcohol", SAE Technical Paper 2015-26-0055, 2015, https://doi.org/10.4271/2015-26-0055.

[14] Sathiyamoorthi, R., Sankaranarayanan, G., "The Effects of Using Ethanol as Additive on the Combustion and Emissions of a Direct Injection Diesel Engine Fuelled with Neat Lemongrass Oil-diesel Fuel Blend", Renewable Energy, 2017, 101: 747-756.

[15] Özer, S., Vural, E., Özdalyan, B., "Dizel Motorlarında Kanola Yağı Metil Esteri-Dizel Yakıtı Karışımlarının Motor Performansına ve Egzoz Emisyonlarına Etkileri”, Electronic Journal of Vehicle Technologies (EJVT), 2011, 3(1): 9-18.

[16] Sugözü, B., "Influence of Diesel Fuel and Soybean Oil Ethyl Ester Blends on the Performance and Emission Characteristics of a Diesel Engine", International Journal of Automotive Engineering and Technologies,2016, 5: 1-7.

[17] Balamurugan T., Nalini, R., "Experimental Investigation on Performance, Combustion and Emission Characteristics of Four Stroke Diesel Engine Using Diesel Blended with Alcohol as Fuel”, Energy, 2014, 78: 356-363.

[18] Vural, E., Şimşek, D., Özer, S., "The Analysis of the Effect of Diesel Fuel Additive 5\%, Compression Ratio and Injection Pressure on the Performance with Diesel-RK Programme", International Conference on Natural Science and Engineering (ICNASE'16) Kilis, March 1920 2016, 2125-213.

[19] Xue, J., Grift, T.E., Hansen, A.C., "Effect of Biodiesel on Engine Performances and Emissions", Renewable and Sustainable Energy Reviews, 2011, 15(2): 1098-1116. 
[20] Hazar, H., Uyar, M., "Experimental Investigation of Isopropyl Alcohol (IPA)/Diesel Blends in a Diesel Engine for Improved Exhaust Emissions", International Journal of Automotive Engineering and Technologies, 2015, 4(1): 1-6.

[21] Labeckas, G., Slavinskas, S., "The Effect of Rapeseed Oil Methyl Ester on Direct Injection Diesel Engine Performance and Exhaust Emissions", Energy Conversion and Management, 2006, 47(13-14): 1954-1967.

[22] Tutak, W., Jamrozik, A., Pyrc, M., Sobiepański, M., “A Comparative Study of Co-Combustion Process of Diesel-Ethanol and Biodiesel-Ethanol Blends in the Direct Injection Diesel Engine", Applied Thermal Engineering, 2017, 117: 155-163. 